\title{
NUTRITIONAL STATUS OF SUB-SAHARANS RESIDING IN THE CITY OF EL JADIDA - MOROCCO: WEIGHT IN RELATION TO SOCIO-ECONOMIC STATUS
}

\author{
Halima Daif ${ }^{1}$,Hamid Chamlal', Imane Barakat ${ }^{1}$,Mohammed El Ayachi', Rekia Belahsen ${ }^{1}$
}

${ }^{1}$ Laboratory of Biotechnology, Biochemistry and Nutrition, Training and Research Unit on Nutrition and Food Sciences, Department of Biology, Faculty of Sciences, Chouaib Doukkali University, El Jadida 24 000, Morocco

\begin{abstract}
Background. Onset of overweight and obesity has been previously reported as a result of population migration to western countries.

Objective. To determine the nutritional status, weight status and their association with socioeconomic status in subSaharan settled in El Jadida city in a Mediterranean country Morocco.

Materials and methods. A descriptive study was carried out in 2018 on 256 sub-Saharans migrants living in the city of El Jadida in Morocco. Information on socio-economic and socio-demographic characteristics as well as anthropometric measurements was collected. The body mass index (BMI) and abdominal obesity by measuring waist circumference (WC) and waist circumference to hip ratio (WHR) and the distribution of body fat by calculating the sum of skin folds are determined.

Results. Analysis results indicate that height, waist circumference, hip circumference, sum of trunk skinfolds, total sum of skinfolds, and BMI increase with age. The prevalence of underweight decreases with age, overweight was $38.7 \%$ in the youngest age group (18-25 years) and reached higher values after 35 years (44.10\%). In addition, the prevalence of general obesity (based on BMI) increased with age and abdominal obesity (based on WHR and WC) was more marked in sub-Saharan people aged 26 to 35 years. These results also reveal the coexistence of underweight, overweight and obesity in all age groups. The analysis revealed a significant association between several variables and obesity. Significant associations were found between age and BMI $(\mathrm{P}=0.04)$, between level of education (university) and $\mathrm{WHR}(\mathrm{p}=0.02)$, between sex and WHR, and between sex and WC $(\mathrm{p}=0.049)$. The study revealed also that the majority of the study sample gained weight after their settling in the host country.

Conclusions. The study data show that obesity including overweight and abdominal obesity were prevalent among subSaharan migrants residing in the city of El Jadida. This prevalence is associated with socio-demographic and socioeconomic factors.
\end{abstract}

Key words: Morocco, obesity, BMI, WHR, Sub-Saharans, migrant

\section{INTRODUCTION}

Morocco, once considered as a land for short duration stays and of transit to Europe [8] has since the early 2000s become a host country for immigrants from sub-Saharan Africa and the Middle East and, increasingly from Asia and Europe [8]. Thus, following the introduction of certain motivational measures, in particular the adoption of a national immigration and asylum policy since the end of 2013 and the regularization of the situation of some 50,000 foreigners between 2014 and 2018, Morocco has moved from a country of transit to a country of residence mainly for migrants of sub-Saharan origin [8]. The traditional diets in the countries of origin of the latter, as for all populations, have a different composition from that of the host country. As a result, these migrants are forced to adopt new eating habits characterized simultaneously by the traditional food culture of the host country and by a modern diet generated by globalization and / or urbanization [14]. These factors have led in Morocco as elsewhere, to a change in the Moroccan food style as well, both quantitatively and qualitatively as part of the nutritional transition underway in the country $[5,28]$. This transition parallels demographic and epidemiological transitions

Corresponding author: Rekia Belahsen, Laboratory of Biotechnology, Biochemistry \& Nutrition, Training and Research Unit on Nutrition \& Food Sciences, Chouaib Doukkali University, School of Sciences, El Jadida, 24000, Morocco, Phone: 212523342325 or 2126649716 16, Fax: 212523342187 / 4449, e-mail: rbelahsen@yahoo.com or b.rekia@gmail.com

(C) Copyright by the National Institute of Public Health NIH - National Research Institute 
[37] which have favored the development of a number of chronic nutrition-related diseases [32, 37]. Indeed, the emergence of weight excess and obesity in relation to these dietary changes has been associated with the onset of metabolic syndrome, diabetes, hypertension, cardiovascular disease and rheumatologically problems [7, 11]. The onset of overweight and obesity as a result of population migration has been previously reported in communities of American immigrants of various ethnic origins (South / Central America Europe / Russia Africa, Middle East / Asia).

Indeed, a study carried out in 2007 [25] on Asians who settled in the USA for at least 10 years who had a normal weight in their country of origin, and who become overweight in relation, among other things, to dietary changes in the host country [21].

In most countries in sub-Saharan Africa, diets are based on cereals, roots and tubers, little animal products and foods high in fiber and low in fat [1]. Despite a topographically diverse land, with a wide representation of agro ecological climates and a dietary diversity of over 150 food crops of which 115 are indigenous, most diets in sub-Saharan Africa consist mainly of grains or roots [9]. In addition, about $80 \%$ of root crops and tubers in Africa are consumed by the households that grow them, and only small quantities are sent to distant markets, even within the country [11]. These foods are the main sources of energy, representing since the 1960 s, 46 and $20 \%$ respectively of the total intake. The diet is known for very little protein of animal origin, vegetables and fruits rich in micronutrients and diversity of quality. However, due to the high cost of these foods, they are inaccessible, unavailable and unevenly distributed locally or are not a priority for households due to insufficient income to meet the needs of quality food $[9,12]$.

On the other hand, the diet in Morocco is of Mediterranean type, known as one of the healthiest diets [35], with olive oil as the main source of dietary fat and an adequate daily intake of water. The Mediterranean diet also includes moderate consumption of eggs and dairy products, and reduced consumption of red meats, processed meats, and foods high in sugar and fat.

Since diet is an important lifestyle factor, eating habits characterized by an intake of sweets, rice, meats, fruits and vegetables, have been associated with reduced risk of diabetes among Ghanaian immigrants $[13,15]$. Also, the diet of Cameroonians characterized by an intake of fruits, vegetables, tubers and legumes has been reported to be associated with a reduced risk of hypertension [30]. In addition, with the advent of globalization and economic development in low and middle income countries (LMICs), a westernization of diets rich in added sugars, fats and foods of animal origin is observed [36]. Migration to countries with higher income than that of the country of origin is also accompanied by potential changes in diet linked to changes in the physical environment and in the eating behavior adopted in the host country [31]. This is reflected in the changes in dietary habits of Ghanaian immigrants in the United Kingdom (UK) [33] and in Europe where an improvement in dietary diversity has also been observed [5] but was, however, associated with cardiovascular disease and the risk of obesity and diabetes type 02 T2DM $[22,39]$.

The present work therefore aims to study the effect of dietary changes and associated factors on the nutritional status of a sub-Saharan population who immigrated to Morocco.

\section{MATERIALS AND METHODS}

\section{Study population}

This study was carried out on a sample of subSaharan migrants residing for at least one year, in El Jadida, a province in the north-west of Morocco. This descriptive study took place between May 2018 and January 2020. The study involved a random sample of 256 men and women (non-pregnant), aged 18 and over and belonging to different social classes (students, employees, traders, etc.). Residence in the city of El Jadida (Moroco) for at least one year was the inclusion criterion, while being pregnant was an exclusion criterion for women, to avoid biasing the results regarding anthropometric measurements. A questionnaire was designed to collect information on socio-demographic and socio-economic characteristics and anthropometric parameters were measured. Before being included in the survey sample, participants signed a consent agreement after being informed about the purpose of the study.

The sociodemographic characteristics collected were: sex, age, marital status, monthly income and education level. The following anthropometric measurements were carried out in accordance to the standards recommended by the World Health Organization (WHO) [22].

The body weight with light clothing and without shoes was measured in the respondents, to the nearest $0.1 \mathrm{~kg}$, using a standard beam scale (Scale 500, Decathlon Morocco). Height was measured using a tape measure with heels joined together against the wall, legs straight, shoulders relaxed, arms hanging out and head resting on the wall. Waist circumference (WC) was measured on respondents in a standing position with feet $25 \mathrm{~cm}$ apart, using a tape that was placed uncompressed midway between the iliac crest and the last rib of ribcage. Waist circumference was obtained using the average of two measures. The hip circumference measurement (HC) was taken on participants in a standing position with their feet 
together and the tape measure placed around the buttocks at the level of the pubic symphysis and the fleshy part of the buttocks.

The amount and distribution of body fat is assessed by measuring the thickness of the subcutaneous fatty tissue folds at 4 sites using a Lange Skinfold Caliper (Lange Skinfold Caliper" Cambridge Scientific Industries, Inc. Cambridge, Maryland). All skin fold thicknesses are measured on the left side of the body at four sites: the biceps, the triceps (limb), the subscapular is and the suprailiac (trunk) skinfolds. The sum of the four measured skinfold thicknesses was considered to be an indicator of total subcutaneous fat while the sum of the trunk skinfold thicknesses as an index of central obesity.

BMI was calculated by dividing body weight in kilograms by the square of height (in $\mathrm{m}$ ). The WC to $\mathrm{H}$ (WHR) ratio is used to assess the distribution of body fat and specifically as indicators of visceral or abdominal fat deposition. [23]. The participants are classified as with high or normal WCs based on gender-specific cutoffs for increased cardiometabolic risk (high WC: in women $\geq 88 \mathrm{~cm}$, men $\geq 102 \mathrm{~cm}$ ) [33]

Participants were divided into BMI categories based on World Health Organization / National Institutes of Health guidelines with underweight (BMI $<18.5 \mathrm{~kg} / \mathrm{m}^{2}$ ), normal weight (BMI 18, 5-24.9 $\mathrm{kg} / \mathrm{m}^{2}$ ), overweight (BMI 25-29.9 $\mathrm{kg} / \mathrm{m}^{2}$ ) and obese $\left(\mathrm{BMI} \geq 30.0 \mathrm{~kg} / \mathrm{m}^{2}\right)$. [30]

Waist-to-hip ratios (WHR) were obtained by dividing the waist circumference by the hip circumference. Men with WHR $<0.90,0.90-0.99$, and $\geq 1.0$ are considered to be normal weight, overweight or obese respectively, while women classified in the same weight categories are respectively considered to be normal weight. $0.80 ; 0.80-0.84$ and $\geq 0.85$, [22]. In addition, the WHO defined the risk zones following the RTH report as being $>0.90$ for men and $>0.85$ for women [33].

The length of residence was calculated in months from the arrival of sub-Saharan participants in Morocco to the date of the survey.

\section{Data analysis}

The data collected was analyzed using the version 21 of SPSS Software for Windows (Statistical Package for Social Sciences). Statistical analysis included description of the characteristics of the study population and the determination of the means of anthropometric variables. The ANOVA test was used to compare the means of anthropometric variables in the different categories of age, gender, education level, marital status and length of residence. The $\mathrm{Chi}^{2}$ test was used to determine the associations between BMI, WHR, WC and the age groups. Simple logistic regression was also used to search for possible risk factors determining general or abdominal obesity by calculating OR. The $p$ value $\leq 0.05$ was set as threshold for statistically significant differences.

\section{Ethical considerations}

Participants in this survey were informed about the study objectives and the possibility for them to interrupt their participation to the survey at any time if they so wish. They signed a free and informed consent before being included in the study sample. All data collected has been treated as strictly confidential.

\section{RESULTS}

The socio-economic and socio-demographic characteristics are presented in Table 1. The Table shows that $55.1 \%$ of the sub-Saharans participating in the present study, were men and $44.9 \%$ were women with the majority of them being single and more than $80 \%$ had a monthly income of less than 3000 MAD. In addition, $13 \%$ of the respondents were illiterate and almost half had a university education level, representing a percentage of $46.9 \%$.

Table 1. Socioeconomic and sociodemographic characteristics of the migrants studied

\begin{tabular}{|c|c|c|c|}
\hline \multicolumn{2}{|c|}{ Variables } & $\mathrm{N}$ & $\%$ \\
\hline \multirow{2}{*}{ Sex } & females & 141 & 55.1 \\
\hline & males & 115 & 44.9 \\
\hline \multirow{3}{*}{ Age groups } & $18-25 \mathrm{yrs}$ & 110 & 43.0 \\
\hline & $26-35 \mathrm{yrs}$ & 66 & 25.8 \\
\hline & $>36$ yrs & 80 & 31.3 \\
\hline \multirow{5}{*}{ Matrital status } & single & 148 & 57.8 \\
\hline & maried & 72 & 28.1 \\
\hline & widower & 4 & 1.6 \\
\hline & divorced & 28 & 10.9 \\
\hline & cohabitation & 4 & 1.6 \\
\hline \multirow{3}{*}{$\begin{array}{l}\text { Monthly income } \\
\text { (in US dollars) }\end{array}$} & $<300 \$$ & 207 & 80.9 \\
\hline & $300 \$-500 \$$ & 36 & 14.1 \\
\hline & $>500 \$$ & 13 & 5.1 \\
\hline \multirow{3}{*}{ Education attainment } & $<7 \mathrm{yrs}$ & 88 & 34.4 \\
\hline & $7-14$ & 48 & 18.8 \\
\hline & $>14$ yrs & 120 & 46.9 \\
\hline
\end{tabular}

Table 2 presents the data concerning the anthropometric parameters of the sub-Saharans surveyed. The results show that the participants had an average age of $31.21 \pm 10.10$ years, an average weight of $75.82 \pm 15.8 \mathrm{~kg}$ and an average height of $1.75 \pm 0.09 \mathrm{~cm}$. The means of the body mass index (BMI), the waist circumference (WC), the hip circumference $(\mathrm{H})$ and the waist-to-hip ratio (WHR) were respectively 24.56 $\pm 5.0 \mathrm{~kg} / \mathrm{m}^{2}, 82.59 \pm 15.59 \mathrm{~cm}, 98.86 \pm 14.66 \mathrm{~cm}$, and $0.85 \pm 0.2 \mathrm{~cm}$ in these migrants. The Table 2 data also 
Table 2. Anthropometric measurements and duration of residence of the sub-Saharans residing in the province of El Jadida

\begin{tabular}{|c|c|c|c|c|}
\hline & \\
\hline & $\mathrm{N}$ & Mean \pm SD & Min & $\operatorname{Max}$ \\
\hline Age (years) & 256 & $31.21 \pm 10.10$ & 18 & 51 \\
\hline Women & 141 & $31.19 \pm 11$ & 18 & 51 \\
\hline Men & 115 & $31.02 \pm 9.01$ & 19 & 51 \\
\hline Height (m) & 256 & $1.75 \pm 0.09$ & 1.48 & 1.96 \\
\hline Women & 141 & $1.75 \pm 0.09$ & 1.96 & 1.96 \\
\hline Men & 115 & $1.76 \pm 0.09$ & 1.54 & 1.48 \\
\hline Weight (Kg) & 256 & $75.82 \pm 15.80$ & 44 & 125 \\
\hline Women & 141 & $74.94+15.22$ & 44 & 125 \\
\hline Men & 115 & $76.90 \pm 16.49$ & 44.40 & 119.00 \\
\hline $\mathrm{BMI}(\mathrm{Kg} / \mathrm{m} 2)$ & 256 & $24.56 \pm 5.00$ & 16.81 & 42.87 \\
\hline Women & 141 & $24.50 \pm 4.81$ & 16.81 & 42.87 \\
\hline Men & 115 & $24.63 \pm 5.25$ & 17.14 & 41.18 \\
\hline $\mathrm{WC}(\mathrm{cm})$ & 256 & $82.59 \pm 15.59$ & 55 & 130 \\
\hline Women & 141 & $81 \pm 14$ & 61 & 130 \\
\hline Men & 115 & $84 \pm 17$ & 55 & 127 \\
\hline $\mathrm{HC}(\mathrm{cm})$ & 256 & $98.86 \pm 14.66$ & 60 & 184 \\
\hline Women & 141 & $99 \pm 15$ & 65 & 184 \\
\hline Men & 115 & $99 \pm 14$ & 60 & 140 \\
\hline WHR & 256 & $0.85 \pm 0.20$ & 0.38 & 1.63 \\
\hline Women & 141 & $0.85 \pm 0.20$ & 0.38 & 1.63 \\
\hline Men & 115 & $0.85 \pm 0.21$ & 0.45 & 1.41 \\
\hline Sum of trunc skinfold thicknesses (mm) & 256 & $26.91 \pm 12.47$ & 7.00 & 68.00 \\
\hline Women & 141 & $27.28 \pm 12.40$ & 7.00 & 67.00 \\
\hline Men & 115 & $26.45 \pm 12.60$ & 7.00 & 68.00 \\
\hline Sum of all skinfold thicknesses (mm) & 256 & $52.25 \pm 20.61$ & 17.00 & 111.00 \\
\hline Women & 141 & $51.08 \pm 19.77$ & 17.00 & 112.00 \\
\hline Men & 115 & $53.36 \pm 21.41$ & 19.00 & 110.00 \\
\hline$\%$ Fat Mass & 256 & $25.31 \pm 9.43$ & 9 & 51 \\
\hline Women & 141 & $24.88 \pm 8.69$ & 10.79 & 49.38 \\
\hline Men & 115 & $24.63 \pm 8.58$ & 10.03 & 51.83 \\
\hline Residency duration & 256 & $47.40 \pm 24.48$ & 12 & 102 \\
\hline Women & 141 & $48 \pm 23$ & 102 & 102 \\
\hline Men & 115 & $47 \pm 25$ & 12 & 12 \\
\hline
\end{tabular}

Legends: BMI- Body Mass Index; WC- Waist Circumference; HC- Hip Circumference; WHR - Hip Waist Ratio; FMI Fat Mass Index ; N - number; \% - percentage 
show that the participants had an average of the sum of the trunc skin folds of $26.91 \pm 12.47$ while that of the four skinfolds was $52.25 \pm 20.61$. The percentage of body fat in the study population was on average 25.31 with a standard deviation of 9.43 .

Table 3 presents the means of anthropometric measurements among the sub-Saharans studied according to three age groups $(18-25 ; 26-35$ and $>35$ years). The results of the analysis indicate that height, waist circumference, hip circumference, sum of trunk skinfolds, total sum of skinfolds and BMI increase with age.

Table 4 shows that the prevalence of underweight decreases with age while that of general obesity (based on BMI) has increased and that abdominal obesity (based on WHR and WC) was more prominent among sub-Saharans aged 26 to 35 . The prevalence of overweight was $38.7 \%$ among the youngest age group (18-25 years) and reached higher values after 35 years $(44.10 \%)$. The results also show coexistence of underweight, overweight and obese in any age group.

Table 5 shows the association between obesity as determined by BMI, WHR or WC and the socioeconomic characteristics. The analysis revealed a significant association between several variables and obesity. Indeed, significant associations were found between age and BMI $(\mathrm{P}=0.04)$, between education level (university) and WHR $(\mathrm{P}=0.02)$, between sex and WHR and between sex and WC $(\mathrm{P}=0.049)$.

Table 6 presents descriptive statistics of subSaharan people who gained or lost weight after settling in El Jadida in Morocco. The percentage of subSaharans who gained weight was $75.4 \%$ in the total population; it was higher among women $(58 \%)$ than among men (42\%). Referring to age, young people are the most likely to either gain weight or stay that way with a percentage of $38.10 \%$.

\section{DISCUSSION}

The present study examined the determinants of the body fat distribution among sub-Saharans residing in the city of El Jadida in Morocco. Body mass index (BMI), waist circumference (WC) and WC / hip circumference ratio (WHR), in accordance with WHO references [26,39], as well as the thickness of the skin folds, as indicators of body composition, have been evaluated in this work.

Excess body fat is well documented as a risk factor for many chronic diseases such as diabetes, hypertension, hyperlipidemia and cardiovascular disease [36]. All these health problems have been associated with obesity which itself is characterized by a high amount of fat in the body composition. The distribution of body fat, particularly the accumulation of intra-abdominal fat has been reported to be

\begin{tabular}{|c|c|c|c|c|c|c|c|}
\hline $2, \frac{\mathscr{J}}{\pi}$ & ठิ & & & & $\begin{array}{l}\stackrel{0}{0} \\
\stackrel{0}{0}\end{array}$ & $\stackrel{8}{\circ}$ & ڤ̊: \\
\hline$\sum_{i}$ & & 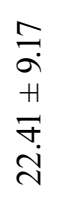 & $\begin{array}{l}\stackrel{0}{0} \\
\infty \\
H \\
\mathbb{N} \\
\stackrel{+}{+}\end{array}$ & $\begin{array}{l}= \\
\infty \\
+ \\
\tilde{\sigma} \\
\hat{\sigma} \\
\end{array}$ & & & \\
\hline $2 \frac{\mathscr{O}}{\stackrel{\pi}{\sigma}}$ & 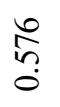 & & & & $\mathscr{\beth}$ & $\mathscr{\beth}$ & $\mathscr{a}$ \\
\hline$\frac{\mathfrak{y}}{3}$ & & 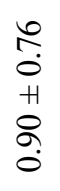 & $\begin{array}{l}m \\
\stackrel{0}{0} \\
+1 \\
n \\
0 \\
0\end{array}$ & $\begin{array}{l}\exists \\
\vdots \\
+1 \\
\infty \\
\infty \\
0 \\
\dot{0}\end{array}$ & & & \\
\hline $2, \frac{\mathscr{g}}{\stackrel{J}{\sigma}}$ & $\stackrel{8}{8}$ & & & & $\stackrel{8}{8}$ & $\begin{array}{l}8 \\
\stackrel{8}{0} \\
\stackrel{0}{0}\end{array}$ & $\stackrel{n}{\stackrel{+}{o}}$ \\
\hline$\sum_{m}$ & & $\begin{array}{l}\mathscr{\alpha} \\
\dot{+} \\
+ \\
\stackrel{\infty}{\infty} \\
\tilde{\sim}\end{array}$ & 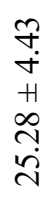 & 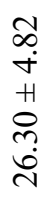 & & & \\
\hline$-\frac{\mathscr{0}}{\frac{\partial}{\pi}}$ & 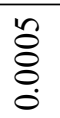 & & & & 官 & $\stackrel{8}{\circ}$ & ț \\
\hline 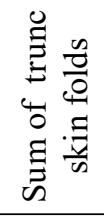 & & 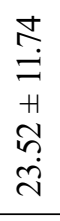 & 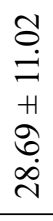 & $\begin{array}{l}n \\
n \\
n \\
+1 \\
\infty \\
\infty \\
0 \\
\infty\end{array}$ & & & \\
\hline $2 \frac{\mathscr{g}}{\frac{\pi}{J}}$ & $\begin{array}{l}1 \\
\delta \\
0 \\
0\end{array}$ & & & & $\stackrel{8}{\circ}$ & $\begin{array}{l}8 \\
\stackrel{8}{\circ} \\
\circ\end{array}$ & 홍 \\
\hline 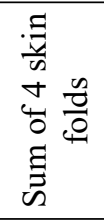 & & $\begin{array}{l}n \\
\tilde{n} \\
0 \\
+1 \\
0 \\
\infty \\
\dot{0} \\
+\end{array}$ & $\begin{array}{l}n \\
n \\
\infty \\
+1 \\
\hat{n} \\
\hat{n} \\
\hat{n}\end{array}$ & 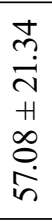 & & & \\
\hline $2 \frac{\mathscr{g}}{\frac{\Xi}{\sigma}}$ & $\begin{array}{l}\infty \\
\stackrel{8}{0} \\
0\end{array}$ & & & & $\frac{n}{0}$ & $\stackrel{n}{0}$ & $\stackrel{f}{\circ}$ \\
\hline U. & & 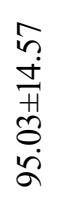 & 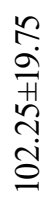 & $\begin{array}{l}\hat{\infty} \\
\text { U. } \\
\text { H } \\
\infty \\
\infty \\
\stackrel{\alpha}{\alpha}\end{array}$ & & & \\
\hline $2, \frac{\mathscr{g}}{\tilde{J}}$ & $\ddot{\tilde{O}}$ & & & & ลิ & $\stackrel{0}{\circ}$ & 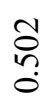 \\
\hline 3 & & $\begin{array}{l}\underset{m}{\infty} \\
\stackrel{n}{+} \\
+ \\
\infty \\
\stackrel{0}{2}\end{array}$ & 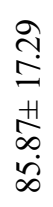 & $\begin{array}{l}0 \\
n \\
0 \\
H \\
\mathbb{N} \\
\infty \\
\infty\end{array}$ & & & \\
\hline & $\stackrel{8}{8}$ & 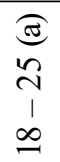 & $\begin{array}{l}0 \\
\tilde{n} \\
\hat{1} \\
0 \\
\sim\end{array}$ & $\begin{array}{l}\tilde{c} \\
\tilde{\wedge}\end{array}$ & $\begin{array}{l}\hat{e} \\
p^{n}\end{array}$ & $\begin{array}{l}0 \\
\frac{n}{>}\end{array}$ & $\begin{array}{l}\text { (e) } \\
y\end{array}$ \\
\hline
\end{tabular}


Table 4. Prevalence of obesity among the sub-Saharan population residing in the city of EL JADIDA by age group

\begin{tabular}{|c|c|c|c|c|c|c|}
\hline Age groups & & $18-25$ yrs & $26-35$ yrs & $>35$ yrs & Total N(\%) & $\mathrm{p}$ value \\
\hline \multirow{4}{*}{ BMI } & Underweight & 60 & 33.30 & 6.70 & $15(5.86)$ & \multirow{4}{*}{0.013} \\
\hline & Normal & 49 & 21.40 & 29.7 & $145(56.64)$ & \\
\hline & Overweight & 38.70 & 27.40 & 33.90 & $62(24.22)$ & \\
\hline & Obesity & 17.60 & 38.20 & 44.10 & 34 (13.28) & \\
\hline \multirow{2}{*}{ WHR } & No Risk & 46.40 & 20.90 & 32.7 & $196(76.56)$ & \multirow{2}{*}{0.005} \\
\hline & Risk & 31.70 & 41.70 & 26.70 & $60(23.44)$ & \\
\hline \multirow{2}{*}{ WC } & No Risk & 47.30 & 22.20 & 30.50 & 203 (79.3) & \multirow{2}{*}{0.009} \\
\hline & Risk* & 26.40 & 39.60 & 34 & $53(20.7)$ & \\
\hline \multirow{2}{*}{ FMI } & Low to normal & 49.6 & 29.3 & 21.1 & $123(48.2)$ & \multirow{2}{*}{0.003} \\
\hline & High & 37.1 & 22.00 & 40.9 & $132(51.8)$ & \\
\hline Total & & 110 & 66 & 80 & $256(100)$ & \\
\hline
\end{tabular}

Legends : WC : Waist Circumference;BMI : Body Mass Index; WHR: Hip Waist Ratio;* : High WC and WHR are of cardiovascular and metabolic risk FMI : Fat Mass Index ; $N$ :number;\%: percentage

Table 5. Association of obesity and socioeconomic and demographic characteristics

\begin{tabular}{|c|c|c|c|c|c|c|}
\hline & \multicolumn{2}{|c|}{ BMI } & \multicolumn{2}{c|}{ WHR } & \multicolumn{2}{c|}{ WC } \\
\hline & p value & $\begin{array}{c}\text { Odds Ratio } \\
(\text { CI at 95\%) }\end{array}$ & p value & $\begin{array}{c}\text { Odds Ratio } \\
\text { (CI at 95\%) }\end{array}$ & p value & $\begin{array}{c}\text { Odds Ratio } \\
(\text { CI at 95\%) }\end{array}$ \\
\hline Sex & 0.23 & $1.38(0.81-2.34)$ & 0.04 & $0.55(0.30-1.00)$ & 0.00 & $10.47(4.68-23.42)$ \\
\hline Age & 0.04 & $1.03(1.00-1.06)$ & 0.67 & $0.99(0.95-1.02)$ & 0.17 & $1.027(0.98-1.06)$ \\
\hline Marital status & 0.73 & $0.95(0.72-1.25)$ & 0.10 & $1.32(0.93-1.87)$ & 0.89 & $0.97(0.67-1.41)$ \\
\hline Education level & 0.37 & $0.91(0.75-1.11)$ & 0.02 & $1.27(1.02-1.58)$ & 0.11 & $0.81(0.64-1.04)$ \\
\hline Monthly income & 0.79 & $0.93(0.57-1.53)$ & 0.41 & $1.27(0.71-2.26)$ & 0.14 & $0.61(0.32-1.18)$ \\
\hline
\end{tabular}

Legend: WC: Waist Circumference; BMI: Body Mass Index; WHR: Hip Waist Ratio; CI: Confidence Interval; $N$ :number;\%: percentage

Table 6. Prevalence of weight status variation in the sub-Saharans migrants after settling in Morocco by sex and age groups

\begin{tabular}{|c|c|c|c|c|c|}
\hline & & $\begin{array}{c}\text { Gained weight } \\
{[\%]}\end{array}$ & $\begin{array}{c}\text { No change } \\
{[\%]}\end{array}$ & $\begin{array}{c}\text { Lost weight } \\
{[\%]}\end{array}$ & $P$ value \\
\hline \multirow{3}{*}{ Age group } & $18-25$ yrs & 38.10 & 38.10 & 44.60 & \multirow{3}{*}{$>0.05$} \\
\hline & $26-35$ yrs & 28.60 & 33.30 & 23.80 & \\
\hline & $>35 \mathrm{yrs}$ & 33.30 & 28.60 & 31.60 & \\
\hline \multirow{2}{*}{ Sex } & Female & 47.60 & 45.20 & 58 & \multirow{2}{*}{$>0.05$} \\
\hline & Male & 52.40 & 54.80 & 42 & \\
\hline \multicolumn{2}{|c|}{ Total N(\%) } & $193(75.4)$ & $21(8.2)$ & $42(16.4 \%)$ & 256 \\
\hline
\end{tabular}

Legend: $N$ - number; \%-percentage 
associated with adverse health consequences and as an important predictor of cardiovascular risk [13, 14, $15,16,23,33]$.

Studies on anthropometry, in particular fat measurements, among people in North African countries are limited $[31,38]$ as is sub-Saharan Africa that only used weight and weight (BMI) as corpulence indicators to assess the prevalence of overweight and obesity.

Data from the High Commission for Planning (HCP) survey on household living standards in 20062007 among the Moroccan population also showed that the scourge of overweight and obesity has not spared Morocco. Obesity was, indeed estimated in 2007 as nearly $11.3 \%$ among adults aged 20 and over, with $8.9 \%$ in the stage of severe obesity and nearly $2.4 \%$ suffering from severe morbid obesity. In subSaharan Africa (SSA), although undernutrition is still widespread, the prevalence of overweight and obesity is steadily increasing. Consistent with the migrant data from the present study, more recent research from the SSA region has reported significant increases in overweight and obesity rates, especially among populations living in urban areas. Indeed, a study carried out in 2016 among 5,190 sub-Saharan Africans, aiming at determining the interrelationships between the main anthropometric indices (BMI, WC, WHR) for the measurement of overweight and obesity in a poor urban environment, confirmed the constant increase in overweight and obesity in subSaharan Africa (SSA) [34]. Consequently, the rates of cardio-metabolic diseases could increase with these prevalence increases of overweight and obesity in SSA [40] and would present an additional burden to the problems of undernutrition, because of the precariousness health care system in these developing countries to fight against the increase in these diseases [2].

In addition, BMI has traditionally been considered the best anthropometric standard for measuring obesity in adults. Most BMI standards used were created based on population samples composed of Caucasians and calculated using height and weight measurements. Research has shown that BMI alone may not be an appropriate tool for determining obesity today, due to differences in ethnicity and individual genetics [34]. In our analysis, the discrepancy between BMI and other indices was high, indicating that BMI was the lowest measure of obesity compared to other indices [34].

The present study revealed high prevalence of overweight (62\%) and obesity (34\%) among surveyed sub-Saharans migrants. In addition except the WHR ratio, all anthropometric data including WC, hip circumference, sum of all skin folds, sum of the trunk skin folds and the BMI, depend on age with a high risk estimated by as high WC ( $\geq 88 \mathrm{~cm}$ in women and $\geq 102$ $\mathrm{cm}$ in men) [33], more particularly in young people of less than 35 years old indicating that accumulation of intraabdominal fat begin early in the youngest age group. These results corroborate with those found in Arab Gulf women [26].

The $C h i^{2}$ analysis table shows that the prevalence of overweight was higher among the young age group people (18-25 years) whereas the prevalence of obesity is increasing with age achieving almost double in age between 26 to 35 yrs old and in the youngest age group (of 18 to $25 \mathrm{yrs}$ ). Similar trends were found for the prevalence of central obesity estimated by fat deposition as high WHR and high WC. These results indicate an increasing fat mass with age in this population, especially in younger people age groups warning on an increase of obesity-related diseases in this population in the future. Similar observations were reported by studies carried out Nigerian populations [27]. Contrary to the above, a recent study carried out on sub-Saharans found also higher prevalence's of obesity and overweight in older groups [34]. Indeed, a high prevalence of overweight and obesity has been found particularly at an age above 35 years in Cameroonian urban populations [29]. The study revealed also that the majority of the study sample gained weight after their settling in the host country. This result is in accordance with previous studies on migrant of various ethnic origin which become overweight or obese once moving to USA [21, 25]. This result could be related to the improvement of their socioeconomic status but other environment factors linked to the observed weight excess need to be explored in this migrant population.

\section{CONCLUSION}

In conclusion, our results suggest that the anthropometric parameters used here could be useful to characterize overweight and obesity (body fat and fat distribution). The study provides insight into the relationship between overweight and obesity using different anthropometric parameters and the socioeconomic characteristics, age and gender.

Based on BMI alone, the study showed a high prevalence of overweight and obesity in the young population which could be due to the change of residence and to the socioeconomic status improvement. The results provides evidence for supporting the establishment of an intervention program to preventing increases of obesitylinked diseases such as diabetes, hypertension, atherosclerosis and their future complications in subSaharan migrants populations residing in Moroccan urban areas. In the meantime, more studies must be carried out to investigate the environmental causes of 
this obesity in the sub-Saharan culture as well as the influence of the Moroccan diet.

\section{Acknowledgments}

Our thanks go to all the sub-Saharans participating in this study for their dedication and their cooperation which helped to facilitate the achievement of the work objectives. We thank the decision makers of the province of El Jadida for their contribution to facilitate access and collection of data. The authors also thank the delegate of the Ministry of Health of El Jadida province. The study was supported by the Ministry of Higher Education and Research, Morocco.

\section{Conflict of interest}

The authors declare no conflict of interest.

\section{REFERENCES}

1. Ali, R.A.B., Harraqui, K., Hannoun, Z., Monir, M., Samir, M., Anssoufouddine, M., Bour, A.: Transition nutritionnelle, prévalence de la double charge de la malnutrition et facteurs de risque cardiovasculaires chez les adultes de l'île comorienne d'Anjouan. Pan African Medical Journal, March 2020, vol. 35. https:// doi.org/10.11604/pamj.2020.35.89.19043

2. Bellamy, N.: Validation study of WOMAC : a health status instrument for measuring clinically important patient-relevant outcomes following total hip or knee arthroplasty in osteoarthritis. Journal of Rheumatology and Orthopedics 1988; 1: 95-108.

3. Benjelloun, S.: Nutrition Transition in Morocco. Public Health Nutrition, 2002;5(1a):13540. https://doi. org/10.1079/PHN2001285.

4. Commodore-Mensah Y, Nwakaego U, Olawunmi $O$, Jonathan KA, Charles A, Carolyn M. Reilly, Sandra B. Dunbar, et Ike S. Okosun: Length of Residence in the United States Is Associated With a Higher Prevalence of Cardio metabolic Risk Factors in Immigrants: A Contemporary Analysis of the National Health Interview Survey. Journal of the American Heart Association, 2016;5(11). https://doi.org/10.1161/ JAHA.116.004059.

5. Danquah, I., Galbete, C., Meeks, K., Nicolaou, M., Klipstein-Grobusch, K., Addo, J., Aikins, A. de-Graft, Amoah, S. K., Agyei-Baffour, P., Boateng, D., BeduAddo, G., Spranger, J., Smeeth, L., Owusu-Dabo, E., Agyemang, C., Mockenhaupt, F. P., Beune, E., \& Schulze, M. B.: Food Variety, Dietary Diversity, and Type 2 Diabetes in a Multi-Center Cross-Sectional Study among Ghanaian Migrants in Europe and Their Compatriots in Ghana: The RODAM Study. European Journal of Nutrition 2018;.57(8):27232733. https://doi. org/10.1007/s00394-017-1538-4. Downloaded from: https://link.springer.com/article/10.1007/s00394-0171538-4

6. Drewnowski A, Popkin BM.: The Nutrition Transition: New Trends in the Global Diet». Nutrition Reviews
[Internet]. 27 avr 2009;55(2):3143. Downloaded from: https://academic.oup.com/nutritionreviews/articlelookup/doi/10.1111/j.1753-4887.1997.tb01593.x

7. Drewnowski A., Popkin BM.: The Nutrition Transition: New Trends in the Global Diet. Nutrition Reviews, 2009;55(2):3143. https:// academic.oup.com/nutritionreviews/article-lookup/ doi/10.1111/j.1753-4887.1997.tb01593.x

8. Elfane H, Mziwira M, Sahel K, El Jamal S, El Mahri $N$, Kalili $A$, et al.: Association of obesity with the lower limbs osteoarthritis in a community of women from El Jadida province in Morocco. The North African Journal of Food and Nutrition Research. Jull 2019;03(5):156163. https://doi.org/10.5281/zenodo.3267465

9. Fanzo J.: The Nutrition Challenge in Sub-Saharan Africa. UNDP Africa Policy Notes, 2012-012, United Nations Development Programme Regional Bureau for Africa, "undated"..

10. FAO. Profil nutritionnel Marocain, Organisation des Nations Unies pour l'alimentation et l'agriculture ROYAUMEDU MAROC, 2011 ;05(4): 764. Downloaded from: https://www.fao.org/3/bc635f/bc635f.pdf.

11. FAO. Role of roots, tubers and plantains in food security in sub-Saharan Africa. FAO, Rome, Italie. 1986b. 21 p.

12. FAO. Sécurité alimentaire et développement agricole en Afrique subsaharienne, Série aux assistances politiques. FAO 2006, Rome, ISBN 92-5-205544-0, ISSN 19918909

13. Frank, Laura K., Janine Kröger, Matthias B. Schulze, George Bedu-Addo, Frank P. Mockenhaupt, Ina Danquah: Dietary Patterns in Urban Ghana and Risk of Type 2 Diabetes. British Journal of Nutrition, 2014;112(1): 8998. https://doi.org/10.1017/S000711451400052X.

14. Galal, $O$. « Nutrition-related health patterns in the Middle East. ", Asia Pacific journal of clinical nutrition, Sep 2003; 12(3)337-343.

15. Galbete C, Nicolaou M, Meeks K, Klipstein-Grobusch $K$, de-Graft Aikins A, Addo J, et al. «Dietary patterns and type 2 diabetes among Ghanaian migrants in Europe and their compatriots in Ghana: the RODAM study». Nutrition \& Diabetes, Dec 2018;8(1):25. Downloaded from: http://www.nature.com/articles/s41387-0180029-x

16. Goran MI, Nagy TR, Treuth MS, Trowbridge C, Dezenberg C, McGloin A, et al.: Visceral fat in white and African American prepubertal children. The American Journal of Clinical Nutrition, June 1997;65(60: 17031708. Downloaded from: https://academic.oup. com/ajcn/article/65/6/1703/4655468

17. Han TS, Williams K, Sattar N, Hunt KJ, Lean MEJ, Haffner SM.: Analysis of Obesity and Hyperinsulinemia in the Development of Metabolic Syndrome: San Antonio Heart Study. Obesity Research, sept 2002;10(9): 923931. Downloaded from: http://doi.wiley. com/10.1038/oby.2002.126

18. Haregu, T., Oti, S., Egondi, T. et Kyobutungi, C.: Measurement of overweight and obesity an urban slum setting in sub-Saharan Africa: a comparison of four anthropometric indices». BioMed Central Obesity, 2016;3(46). https://doi.org/10.1186/s40608-016-0126-0 . 
19. HCP. Le Haut-Commissariat au Plan met en ligne le rapport des résultats détaillés de l'enquête sur la migration internationale 2018-2019. Downloaded from https:/www.hcp.ma/Le-Haut-Commissariat-au-Planmet-en-ligne-le-rapport-des-resultats-detailles-de-1enquete-sur-la-migration_a2571.html

20.Huang, KC., Lin, WY., Lee, LT. et R-S Lin .Four anthropometric indices and cardiovascular risk factors in Taiwan. Int. J. Obes., 2002;26(8):1060-1068 https:// doi.org/10.1038/sj.ijo.0802047. Downloaded from https://www.nature.com/articles/0802047\#citeas

21. Kamadjeu, R.M., Edwards, R., Atanga, J.S. et al.: Anthropometry measures and prevalence of obesity in the urban adult population of Cameroon: an update from the Cameroon Burden of Diabetes Baseline Survey. BMC Public Health, 2006; 6(1): 228, https://doi. org/10.1186/1471-2458-6-228

22. Kandula, N. R., Diez-Roux A. V., Chan, C. Daviglus, M. L. Jackson, S. A. \& Schreiner. P. J.: Association of Acculturation Levels and Prevalence of Diabetes in the Multi-Ethnic Study of Atherosclerosis (MESA). Diabetes Care, 2008;31(8):16211628. https://doi. org/10.2337/dc07-2182.

23. Kaufman J. S., Owoaje E. E., James S. A., Rotimi C. N., \& Cooper R. S.: Determinants of hypertension in West Africa: contribution of anthropometric and dietaryfactors to urban-rural and socioeconomic gradients. Am. J. Epidem. 1996;143(12) p. 1203-1218.

24. Klein S, Allison D.B., Heymsfield S.B., Kelley D.E., Leibel R.L., Nonas C., Kahn R.: Waist Circumference and Cardiometabolic Risk: A Consensus Statement from Shaping America's Health: Association for Weight Management and Obesity Prevention; NAASO, The Obesity Society; the American Society for Nutrition; and the American Diabetes Association., s. d., 6. Am. J. Clin. Nutr. 2007;85(5):1197-1202. Downloaded from https:// academic.oup.com/ajcn/article/85/5/1197/4633199

25. Koya DL., Egede LE.: Association Between Length of Residence and Cardiovascular Disease Risk Factors Among an Ethnically Diverse Group of United States Immigrants. Journal of General Internal Medicine, Mai 2007;22(6):84146. https://doi.org/10.1007/s11606-0070163-y.

26. Kuczmarski R.J., Flegal K.M: Criteria for definition of overweight in transition: background and recommendations for the United States. The American Journal of Clinical Nutrition, Nov 2000; vol. 72, $\mathrm{n}^{\circ}$ 5, p: 1074-1081. https://doi.org/10.1093/ajcn/72.5.1074

27. Little M., Humphries S., Patel K., Dewey C.: Factors associated with BMI, underweight, overweight, and obesity among adults in a population of rural south India: a cross-sectional study». BioMed Central Obesity, 2016;3(1):1-13. Downloaded from: https://bmcobes. biomedcentral.com/articles/10.1186/s40608-016-0091-7

28. Luke, A., Cooper R. S., Prewitt, T. E., Adeyemo, A. A., et Forrester, T. E.: Nutritional consequences of the African diaspora. Annu Rev Nutrit. 2001;21(1):47-71,. https://doi.org/10.1146/annurev.nutr.21.1.47

29. Mokhtar N., Elati J., Chabir R., Bour A., Elkari K., Schlossman N.P., Caballero B., Aguenaou
H.: Diet Culture and Obesity in Northern Africa. Journal of Nutrition, Avr 2001:131(3):887S-892S. Downloaded from https://academic.oup.com/jn/ article/131/3/887S/4687034

30. Nkondjock A., Bizome E. Dietary patterns associated with hypertension prevalence in the Cameroon defense forces. The European Journal of Clinical Nutrition, Sept 2010;64(9):10141021. Downloaded from: http:/ www.nature.com/articles/ejcn2010109

31. Okafor MTC., Carter-Pokras OD., Zhan M.: Greater dietary acculturation (dietary change) is associated with poorer current self-rated health among African immigrant adults. Journal of Nutrition Education and Behavior, 2014;46(4):226-235.

32. Omram A. R.: The epidemiologic transition: a theory of the epidemiology of population change. Bulletin of the World Health Organization, 2001;79:161-170.

33. Osei-Kwasi HA., Powell K., Nicolaou M., Holdsworth $M .:$ The influence of migration on dietary practices of Ghanaians living in the United Kingdom: a qualitative study. Annals of Human Biology, 2017;44(5): 454-463. https://doi.org/10.1080/03014460.2017.1333148

34. Per Björntorp MD.: Metabolic implications of body fat distribution. Diabetes Care, 1991;14(12):11321143.

35. Popkin B. M.: The nutrition transition and obesity in the developing world. Journal of Nutrition, 2001;131(3): 871S-873S.

36. Popkin BM., Adair LS., Ng SW: Global nutrition transition and the pandemic of obesity in developing countries». Nutrition Reviews, 2012;70(1): 3-21.

37. Popkin BM., Gordon-Larsen P.: The nutrition transition: worldwide obesity dynamics and their determinants., Int. J. Obes., 2004;28(3): S2-S9.

38. Pouliot M.C., Després J.P., Lemieux S., Mourjani S., Bouchard C. Tremblay A., Paul J.L.: Waist circumference and abdominal sagittal diameter: best simple anthropometric indexes of abdominal visceral adipose tissue accumulation and related cardiovascular risk in men and women. Am J Cardiol. 1994;73(7):460468.

39. Regev-Tobias H., Reifen R., Endevelt R., Havkin O., Cohen E., Stern G., Stark A.: Dietary acculturation and increasing rates of obesity in Ethiopian women living in Israel. Nutrition, 2012;28(1): 30-4.

40.Scott, A., Ejikeme, C. S.; Clottey E. N., Thomas, J. G.: Obesity in sub-Saharan Africa: development of an ecological theoretical frame work. Health Promotion International, 2013;28(1):4-16,

41. St-Pierre J., Lemieux I., Vohl M-C., Perron P., Tremblay G., Després $J-P$, et al.: Contribution of abdominal obesity and hypertriglyceridemia to impaired fasting glucose and coronary artery disease. Am J. Cardiol. 2002Jul;Vol.90(1):15-18. Downloaded from: https://linkinghub.elsevier.com/retrieve/pii/ S0002914902023780.

42. Willett W. C., Sacks F., Trichopoulou A., Drescher G., Ferro-Luzzi A., Helsing E., Trichopoulos D.: Mediterranean diet pyramid: a cultural model for healthy eating. Am J Clin. Nutr., 1995;61(6):1402S-1406S. 
43. WHO. Consultation on Obesity (1999): Geneva, Switzerland) \& World Health Organization. (2000). Obesity: preventing and managing the global epidemic: report of a WHO consultation. World Health Organization. 2010 Downloaded from https://apps.who.int/iris/ handle/10665/423300
44. WHO. Diet, nutrition and the prevention of chronic diseases. World Health Organization technical report series, 2003;916:i-viii, p: 1-149,. PMID: 12768890.

Received: 22.09 .2021

Accepted: 18.10 .2021

Published online first: 09.11.2021 